Ministero della Salute (2001) Assistenza Psichiatrica in Italia. Rome: Ministero della Salute.

Mosher, L. R. (1982) Italy's revolutionary mental health law: an assessment. American Journal of Psychiatry, 139, 199-203.

Perris, C. \& Kemali, D. (1985) Focus on the Italian psychiatric reform: an introduction. Acta Psychiatrica Scandinavica Supplementum, 316, 9-14.

Putnam, R. D. (1993) Making Democracy Work. Civic Traditions in Modern Italy. Princeton, N J: Princeton U niversity Press.
Saraceno, B. \& Tognoni, G. (1989) Methodological lessons from the Italian psychiatric experience. International Journal of Social Psychiatry, 35, 98-109.

Warner, R., de Girolamo, G., Belelli, G., et al (1998) The quality of life of people with schizophrenia in Boulder, Colorado, and Bologna, Italy. Schizophrenia Bulletin, 24, 559-568.

World Bank (2003) Data from the website www.worldbank.org. World Health Organization (2003) Data from the website www.who.int

\title{
The Association of European Psychiatrists' programme of itinerant CME courses
}

\section{Mario Maj}

President, Association of European Psychiatrists; Clinica Psichiatrica Università, Largo Madonna delle Grazie, I - 80138 Napoli, Italy, email majmario@tin.it

ccording to the most recent data provided by the World Health 0 rganization (2001), there are presently in Europe more than 77000 psychiatrists, more than 46000 clinical psychologists active in the mental health field, more than 285000 psychiatric nurses, and more than 91000 social workers operating in the mental health sector. Are these professionals being adequately updated on recent clinical and service developments in mental health? What is the role of international channels (in particular, those of international professional associations) in this process? These are difficult questions to answer, in the absence of a European systematic survey (which, of course, would be a very worthwhile initiative). I try, however, to provide here a framework for a discussion of these issues, as a background to the presentation of the programme of itinerant educational courses run by the Association of European Psychiatrists (AEP).

\section{The main channels}

The main international channels of professional update in the mental health field are scientific meetings, traditional publications (i.e. professional journals, books and other printed materials), the internet and the direct channels used by drug companies.

\section{Scientific meetings}

A w ell-organised international meeting offers a variety of opportunities for update, from state-of-the-art lectures to workshops and educational courses. Several international meetings offer a programme of continuing medical education (CME) courses, with provision of credits.

The problem is, how ever, that the average European psychiatrist is often unable to afford the registration fee, so that his or her participation often depends on sponso rship by a drug company. This means that psychiatrists who do not have relationships with drug companies are penalised in their access to professionally relevant information. This is the case for virtually all psychiatrists of some European countries which are not very attractive to drug companies, in particular in eastern Europe. For instance, during the AEP CME course held in Almaty, Kazakhstan, on 6 June 2003, the participants were asked to complete a questionnaire concerning their previous participation in international psychiatric congresses. 0 ut of the 56 participants on the course, who were likely to represent a selected group of highly motivated psychiatrists, only two had ever participated in a W orld Congress of Psychiatry, and none had ever attended a Congress of the AEP, the European College of N europsychopharmacology (ECN P), the Collegium Internationale N europsychopharmacologicum (CIN P) or the American Psychiatric Association (APA). For those who may think that this is a marginal problem, it is useful to point out that the number of psychiatrists who are currently active in Kazakhstan is about 1000.

The European audience of international psychiatric meetings is represented by a restricted elite, mostly consisting of psychiatrists from 'group $A^{\prime}$ countries of the World Bank classification (i.e. those with the highest income per capita). Moreover, the participation of European mental health professionals other than psychiatrists is usually very limited.

Traditional publications

In psychiatry and related mental health disciplines, there are presently 89 jo urnals for which the Institute of Scientific Information reports an impact factor, of which 76 are produced in English. Most of these journals have an international distribution, but the vast majority and sometimes the to tality of their subscribers are from $\mathrm{N}$ orth America, Western Europe and Australia. The average European psychiatrist (especially from a group $B, C$ or D country) cannot afford the cost of the subscription to even one international journal. Moreover, in many European countries, libraries where international psychiatric journals can be found are few and difficult to access; in several group C or D European countries, no such library is available. Furthermore, many academic centres, even in group A European countries, are currently reducing the number of journals to which they subscribe.
For contributions to the Associations and Collaborations column, please contact Dr John Henderson: john.henderson53@ btopenworld.com

\section{atopenworld.com}


Financial and logistic difficulties are not the only obstacles to the access of European psychiatrists to international journals. Many European clinicians, even if they are able to read English (which is not the case for several thousands of psychiatrists in Europe), experience increasing difficulties in understanding the technical details of some papers published in international journals - indeed, the contents of some international journals are becoming less and less accessible to clinicians.

Finally, few clinical psychologists and other mental health professionals have access to international mental health journals in most European countries.

The offer of books in the mental health field is rich and

What should be

the role of

international

professional

associations? Can

they do more than

organise scientific

meetings for a

small minority of

European psychi-

atrists, or publish

journals and

books for an even

more limited

audience, or make

attempts to

harmonise

national CME

programmes

(which in several

cases exist only on

paper)? varied. However, access to books is even more limited than to journals. The cost of books is often prohibitive for the vast majority of professionals. Even many academic centres in group $B, C$ or D European countries cannot afford to purchase them. Access to individual chapters of published books is much more difficult than to papers published in international journals. This is one of the reasons why books are increasingly becoming a vehicle for theoretical essays or reviews of the literature rather than for new information.

It is useful to emphasise that the majority of international psychiatric journals largely depend for their survival on advertisements by drug companies, and that many publishing companies require the author of a book to ensure that a certain number of copies be purchased by a sponsor, which is usually a drug company.

The internet

The role of the internet in the dissemination of information in the mental health field is becoming more and more significant. The main problem with this information is its very varied quality and credibility. International professional associations have a very important role to play here, not only by providing information and educational materials on their own websites, but also by developing rules with which their members have to comply in the provision of information, as well as a system of accreditation of the information which appears on-line, as a guide for users.

\section{The drug companies}

Besides funding, directly or indirectly, the majority of the above-mentioned channels by which information is disseminated in the mental health field, drug companies are increasingly developing their own, direct channels. In addition to traditional leaflets focusing on their products, they often distribute proceedings of symposia they have sponsored, reprints of articles published in international journals and other printed materials. M oreover, several companies now invite internationally renowned researchers with whom they have good relationships to deliver seminars in several centres, with the participation of many hundreds of psychiatrists, including many who do not usually attend international scientific meetings.

\section{The role of international professional associations}

In this situation, what should be the role of international professional associations? C an they do more than organise scientific meetings for a small minority of European psychiatrists, or publish journals and books for an even more limited audience, or make attempts to harmonise national CME programmes (which in several cases exist only on paper)? Can these associations do more for psychiatrists of those European countries which are currently almost forgotten by the international psychiatric community? I believe that not only can they do so, but they have the duty to do so, and that the crucial step is the establishment of a close collaboration with national psychiatric societies. These societies should be provided not only with rules and guidelines, but also with concrete support, for example in the form of internationally renowned teachers and high-quality educational materials, following their own priorities rather than those of any sponsor or of any European body.

Table 1. Calendar of AEP itinerant CME courses for the second half of the year 2003

\begin{tabular}{|c|c|c|c|c|}
\hline Date & Location & Collaborating body & Title & Director(s) \\
\hline 2 June & Tel Aviv, Israel & Israeli Psychiatric Association & $\begin{array}{l}\text { How to set up and evaluate a community } \\
\text { mental health service }\end{array}$ & G. Thornicroft, UK \\
\hline 6 June & Almaty, Kazakhstan & $\begin{array}{l}\text { Kazakh Association of Psychiatrists } \\
\text { and Narcologists }\end{array}$ & Trends in drug treatment of schizophrenia & F.-A. Wiesel, Sweden \\
\hline 11 June & Oviedo, Spain & Spanish Association of Neuropsychiatry & $\begin{array}{l}\text { How to set up and evaluate a community } \\
\text { mental health service }\end{array}$ & $\begin{array}{l}\text { G. Thornicroft, UK; } \\
\text { M. Tansella, Italy }\end{array}$ \\
\hline 13 August & Reykjavik, Iceland & Icelandic Psychiatric Association & $\begin{array}{l}\text { Cognitive-behavioural therapy in anxiety } \\
\text { disorders }\end{array}$ & L.-G. Ost, Sweden \\
\hline 8 September & Tblisi, Georgia & Society of Georgian Psychiatrists & ADHD through the life span & S. Tyano, Israel \\
\hline 15 October & Antalya, Turkey & Psychiatric Association of Turkey & Alcohol dependence & K. Mann, Gernmany \\
\hline 20 October & Bologna, Italy & Italian Psychiatric Association & $\begin{array}{l}\text { Liaison psychiatry: identifying and treating } \\
\text { psychiatric problems in a medical population }\end{array}$ & F. Creed, UK \\
\hline 19-23 November & Berlin, Germany & $\begin{array}{l}\text { German Society of Psychiatry, } \\
\text { Psychotherapy and Neurology }\end{array}$ & $\begin{array}{l}\text { Teaching general practitioners about } \\
\text { depression } \\
\text { Alcohol dependence }\end{array}$ & $\begin{array}{l}\text { J. Cooper, UK } \\
\text { K. Mann, Germany }\end{array}$ \\
\hline
\end{tabular}


The AEP programme of itinerant CME courses (Table 1) represents a first step in this direction. $O$ ur starting point has been the programme ofCME courses delivered at the 11th Congress of the Association in Stockholm in May 2002. This programme included 36 CME courses, all developed under the guidance of an ad hoc committee. These courses were formally evaluated in Stockholm by three groups of assessors: the participants, the teachers and a group of observers appointed by the AEP and the host society, the Swedish Psychiatric Association. Among the courses which received the best ratings, the AEP Executive Committee selected those whose topics were most likely to be of interest to psychiatrists of all the various European countries. The list was then submitted to the presidents of all national psychiatric so cieties, asking them to host one or more of the courses within their national congresses, as a joint initiative of their society and the AEP, providing the same kind of evaluation which took place in Stockholm. Local expenses, including those of simultaneous translation, were to be covered by national societies, whereas the travel expenses and the honoraria for the teachers were to be covered by the AEP. No drug company was to be involved in any way in the organisation of the courses.

To date, concrete agreements have been made with 18 national psychiatric societies for the co-organisation of the courses (the Czech Psychiatric Society; the D anish Psychiatric Association; the Finnish Psychiatric Association; the German Society of Psychiatry, Psychotherapy and $N$ eurology; the Icelandic Psychiatric Asso ciation; the Israeli Psychiatric Association; the Italian Psychiatric Association; the Kazakh Association of Psychiatrists and N arcologists; the Kyrgyz Psychiatric Asso ciation; the Lithuanian Psychiatric Association; the Luxembourg Society of Psychiatry, N eurology and Psychotherapy; the Maltese Psychiatric Association; the Polish Psychiatric Association; the Portuguese Psychiatric Association; the Psychiatric Association of Slovenia; the Psychiatric Association of Turkey; the Society of Georgian Psychiatrists; the Spanish Association of $\mathrm{N}$ europsychiatry). The list of the courses scheduled for the second half of the year 2003 is presented in Table 1.

0 f course, this is just a beginning, and many things can be done to extend the initiative in terms of countries involved, of courses provided, and of participants in each country. However, several principles on which the initiative is based deserve attention:

o the collaboration of an international psychiatric association with national psychiatric societies in Europe in a concrete educational activity

o the implementation of the initiative in individual European countries

O the coverage of all areas of Europe, without exclusion;

o the possibility offered to national societies to choose the to pics and teachers of interest

o the coverage of part of the expenses by the international asso ciation

o the decision not to request the sponsorship of a specific drug company.

In the future, the possibility may be considered of building up a consortium of drug companies covering part of the costs of the initiative. This consortium should not have any role in the selection of the topics, the teachers, or the countries in which the courses have to be implemented. What we are especially explo ring, however, is the possibility to submit to the European Union a comprehensive European educational programme, jointly promoted by the AEP, the European Region of the World Psychiatric Association, the European U nion of Medical Specialists and the European region of the World $\mathrm{H}$ ealth $\mathrm{O}$ rganization, in collaboration with national psychiatric societies in Europe.

\section{Reference}

World Health Organization (2001) Atlas: Mental Health Resources in the World 2001. Geneva: WHO

\section{NEWS, NOTES, FORTHCOMING INTERNATIONAL EVENTS}

\section{News and notes}

For contributions to this column, please contact Dr Brian Martindale, Psychotherapy Department, John Conolly Wing, West London Mental Health NHS Trust, Hanwell UB1 3EU, UK, email brian.martindale@wlmht.nhs.uk

\section{Report on the annual meeting of the Royal College of Psychiatrists, Edinburgh International Conference Centre, 30 June-3 July 2003}

I had spent the best part of a year helping to plan a balanced, scientifically stimulating conference, which also could:

O give delegates an opportunity to participate in interactive sessions and training courses

O give all the different concerns of Faculties, Sections and Special Interest $\mathrm{G}$ roups in the College a place in the metaphorical sun

O and, not least, be financially successful for the College.
O ne would have expected that, by the time of the opening ceremony, I would have been a bundle of nerves in trepidation that, by trying to address all these agendas, we were in real danger of pleasing no one.

$N$ othing was further from the truth. To my admittedly biased but none the less critical eye, the programme looked like it was going to be a success, and the wonderful city of Edinburgh could offer the guarantee that it would lend its $\mathrm{G}$ aelic magic to the conference. $\mathrm{O}$ top of all of this, with the traditional hospitality of our hosts and the efficiency of the College Conference $O$ ffice, I was as cool as a cucumber. I could then switch off from being the organiser to just one more delegate taking advantage of the annual get-together.
What we are especially exploring, however, is the possibility to submit to the

European Union a

comprehensive

European educational programme. 